\title{
EVALUASI PELAKSANAAN PROGRAM RINTISAN PPJJ (PENGEMBANGAN PENDIDIKAN JARAK JAUH) \\ IAIN WALISONGO MENUJU PEMBELAJARAN ONLINE (Kerjasama DBE 2 USAID dengan \\ IAIN Walisongo Semarang)
}

\author{
Nur Khasanah
}

\begin{abstract}
Abstrak
Penelitian ini bertujuan (1) mengetahui hasil pelaksanaan program rintisan pembelajaran jarak jauh dari aspek kesiapan kebijakan institusi, sumber daya manusia serta sarana prasarana, (2) menganalisis hasil pelaksanaan program hingga terumuskan hal-hal yang menjadi indikator kesiapan sekaligus permasalahan untuk lebih siap diimplementasikan pada lingkup yang lebih luas, yaitu di seluruh Fakultas di IAIN Walisongo Semarang.

Penelitian ini dilakukan dengan pendekatan kualitatif. Penelitian ini memaparkan data kualitatif tentang pelaksanaan pembelajaran online dari baik dari aspek partisipasi, konteks sosial maupun organisasional yaitu berupa aspek kesiapan kebijakan institusi, kesiapan sumber daya manusia dan kesiapan sarana prasarana. Sedangkan instrumen pengumpulan data yang digunakan adalah (1) dokumentasi terkait data dosen, data mahasiswa, data mata kuliah, data sarana prasarana serta data teknis lain terkait penyiapan kelas online, (2) instrumen wawancara berupa pedoman wawancara dengan topik terkait pelaksanaan program rintisan PPJJ, (3) instrumen pengamatan yang digunakan untuk mengamati pelaksanaan pembela-
\end{abstract}


jaran dalam kelas online. Selanjutnya, data yang terkumpul dianalisis dengan model evaluasi CIPP (Context, Input, Process, Product) yang dikembangkan oleh Stufflebeam (1971) (Worthen dan Sanders 1973). Menurut model ini ada empat aspek penyelenggaraan rintisan PJJ yang dapat dievaluasi: context, input, process, dan product.

Hasil penelitian ini menunjukkan respon mahasiswa antusias dalam mengikuti pembelajaran online, meskipun masih dijumpai mahasiswa yang kurang aktif karena beberapa sebab. Bagi Dosen dengan PPJJ memberikan bentuk pembelajaran yang berbeda dari model yang sebelumnya sudah dilaksanakan sehingga menambah variasi dalam model pembelajaran. Bagi Dosen,PPJ membutuhkan persiapan serta waktu yang lebih banyak dalam pendampingan proses pembelajaran kelas online yang sedang berlangsung. Infrastruktur Fakultas Tarbiyah yang kurang maksimal dalam memberikan dukungan untuk menunjang pelaksanaan PPJJ merupakan salah satu faktor penghambat.

Penelitian ini diharapkan dapat menjadi masukan penting bagi kesiapan IAIN Walisongo Semarang dalam mengimplementasikan pembelajaran online pada waktu mendatang.

Kata kunci: PPJJ, kelas online 


\section{PENDAHULUAN}

Teknologi telah menjadi tools (alat bantu) yang jamak digunakan dalam beragam aktifitas. Dalam Kamus Besar Bahasa Indonesia (1990), teknologi didefinisikan sebagai keseluruhan sarana untuk menyediakan barang-barang yang diperlukan bagi kelangsungan dan kenyamanan hidup manusia. Bahkan paradigma "teknologi informasi menembus ruang dan waktu" semakin menguatkan bahwa pada masa sekarang ini tidak ada aktifitas yang bisa berjalan efektif tanpa campur tangan teknologi.

Salah satu bidang yang mendapatkan dampak cukup berarti akan perkembangan teknologi adalah bidang pendidikan, dimana pada dasarnya pendidikan dengan inti proses "transfer knowledge" merupakan suatu proses komunikasi informasi antara pendidik dengana peserta didik, yang didalamnya berisi informasi-informasi pendidikan, yang memiliki unsur-unsur, pendidik sebagai sumber informasi, media sebagai sarana penyajian ide, gagasan dan materi pendidikan, serta peserta didik itu sendiri sebagai penerima informasi (Oetomo dan Priyogutomo, 2004). Beberapa unsur berbasis informasi dalam pendidikan sangat berpotensi mendapatkan sentuhan media teknologi informasi yang sekarang ini identik dengan perangkat elektronik berbasis koneksi jarak jauh seperti komputer dan internet.

Komputer mendukung perancangan, pembuatan dan pengelolaan beragam media pendidikan sehingga lebih efektif, berkualitas dan menarik. Seperti disebutkan AECT (2004) bahwa

"Educational technology is the study and ethical practice of facilitating learning and improving performance by creating, using, and managing appropriate technological processes and resources."

artinya implementasi teknologi bertujuan utama untuk memfasilitasi pembelajaran agar efektif, efisien, menarik/joyfull serta dapat meningkatkan kinerja. Disisi lain, internet sebagai satu bentuk inovasi sistem komputerisasi memiliki pula fungsionalitas khusus. Sebagai bentuk teknologi komputer berbasis jaringan, internet mampu mendekatkan dan mempercepat transformasi informasi. Pendidikan memerlukan teknologi internet dalam rangka mempercepat akselerasi ilmu pengetahuan. 
Terlebih pada masa sekarang ini internet bukanlah "barang mahal". Menurut data Kementerian Komunikasi dan Informatika, pengguna internet telah mencapai 45 juta orang (Rakernas APJII 2010) atau $19 \%$ dari jumlah penduduk Indonesia. Layaknya telepon, orang telah terbiasa berinteraksi dengan internet bahkan internet seakan sudah menjadi gaya hidup.

Di Indonesia khususnya dalam dunia pendidikan, mulai sekitar tahun 1994-1998, sebuah perusahaan telekomunikasi milik negara telah memperkenalkan "Internet Goes To School/IG2S" sebagai terobosan internet murah untuk sekolah. Dengan IG2S, siswa belajar tentang komunikasi elektronik seperti email, chatting, mailing list serta optimalisasi search engine untuk pencarian informasi. Upaya demikian sungguh patut diapresiasi meski sangatlah sulit program IG2S ini dapat menjangkau keberadaan pendidikan di 17.504 pulau di Indonesia.

Pada akhirnya, PR (pekerjaan rumah) berkaitan kesenjangan akselerasi ilmu pengetahuan yang terjadi di Indonesia dan masih belum terpenuhinya pemerataan pendidikan menjadikan perlu adanya pendidikan jarak jauh sebagai solusi cerdas. Seperti disampaikan oleh Menteri Pendidikan Nasional, Mohammad Nuh, bahwa pendidikan jarak jauh sangat penting untuk jumlah penduduk yang sangat besar, sebab bila mengandalkan pembelajaran konservatif, diperlukan infrastruktur yang sangat luar biasa (Suara Merdeka, Sabtu 5 Pebruari 2011). Sesuai dengan fungsionalitasnya, internet merupakan sebuah alternatif media pendidikan jarak jauh yang efektif.

Distance Learning atau electronics learning adalah sebuah konsep pendidikan jarak jauh yang dilakukan dengan teknologi internet sebagai medianya. Semakin murahnya biaya akses internet serta semakin luasnya jangkauan pembangunan infrastruktur jaringan internet di daerah-daerah diharapkan mendukung keberhasilan program pendidikan jarah jauh berbasis internet ini. Dalam konteks yuridis formal, seperti yang termuat dalam PP No.17 Tahun 2010, bab IV tentang penyelenggaraan Pendidikan Jarak Jauh (PJJ), memiliki tujuan untuk perluasan dan pemerataan akses pendidikan, serta meningkatakan mutu 
dan relevansi pendidikan.

Sebuah badan kerjasama antara pemerintah Indonesia dan pemerintah Amerika Serikat dalam bidang peningkatan program pengajaran dan pembelajaran bernama Decentralized Basic Education 2 (DBE2) USAID membuat portal layanan pendidikan jarak jauh bernama ptk-online.org yang dipergunakan sebagai sarana peningkatan profesionalisme Pendidik dan Tenaga Kependidikan (PTK). Saat ini DBE2-USAID lewat program pengembangan profesionalisme secara online telah menjangkau lebih dari 300 pendidik dan tenaga kependidikan sejak diluncurkan pertama kali pada bulan Maret 2009. Bentuk kegiatan berupa pendampingan terhadap tenaga pendidik pada jenjang pendidikan dasar dan menenegah dalam hal penggunaan teknologi dalam pendidikan. Mulai tahun 2010, DBE2 memperluas jangkauan program pada jenjang pendidikan tinggi. Sejumlah 11 perguruan tinggi di Indonesia mengawali kerjasama rintisan tersebut. Kesebelas perguruan tinggi tersebut adalah Universitas Negeri Makassar, Universitas Negeri Malang, Universitas Negeri Sebelas Maret, Universitas Kristen Satya Wacana, Universitas Negeri Semarang, Universitas Syiah Kuala, Universitas Muhammadiyah Aceh, Universitas Negeri Medan, Universitas Negeri Surabaya, IAIN Sumatera Utara dan IAIN Walisongo Semarang.

IAIN Walisongo dalam hal ini diwakili oleh Fakultas Tarbiyah, menyambut baik dan mengikuti secara aktif program rintisan Pengembangan Pendidikan Jarak Jauh ini mulai bulan Juni 2010. Tahun 2010 merupakan tahap pertama atau tahap rintisan yang berupa kegiatan pelatihan dan pendampingan tentang cara perancangan dan pengelolaan kelas online. Tahap rintisan ini hanya diikuti oleh 10 dosen. Selanjutnya tahap tindak lanjut dilakukan pada awal tahun 2011 berupa kegiatan implementasi kelas online secara terbatas bagi dosen-dosen yang telah mendapatkan pelatihan dan pendampingan pada tahap rintisan.

Bagi institusi IAIN Walisongo Semarang, kerjasama pengembangan pendidikan jarak jauh ini diharapkan mampu memberikan inovasi bagi berlangsungnya pembelajaran yang sekaligus dapat meningkatkan kualitas pembelajaran. Menin- 
gkatnya kualitas pembelajaran adalah suatu bentuk penguatan akademik yang harus dilakukan IAIN Walisongo mengingat peran strategis IAIN Walisongo sebagai perguruan tinggi negeri berbasis keagamaan Islam di ibukota propinsi Jawa Tengah.

\section{RUMUSAN MASALAH}

Berdasarkan paparan di atas, kiranya perlu dilakukan evaluasi terhadap pelaksanaan program pengembangan pendidikan jarak jauh (PPJJ) di Fakultas Tarbiyah agar dapat menjadi dasar dalam melihat kesiapan IAIN Walisongo menuju pembelajaran online khususnya kesiapan dalam aspek-aspek permasalahan sebagai berikut :

1. Bagaimana hasil pelaksanaan program rintisan pengembangan pendidikan jarak jauh (PPJJ) dalam hal kesiapan pimpinan untuk mengimplementasikan program?

2. Bagaimana hasil pelaksanaan program rintisan pengembangan pendidikan jarak jauh (PPJJ) dalam hal kesiapan sumber daya manusia?

3. Bagaimana hasil pelaksanaan program rintisan pengembangan pendidikan jarak jauh (PJJ) dalam hal kesiapan sarana prasarana?

4. Dapatkah hasil pelaksanaan program rintisan pengembangan pendidikan jarak jauh (PJJ) di Fakultas Tarbiyah ditindaklanjuti untuk diterapkan di lingkup institusi IAIN Walisongo Semarang?

\section{TUJUAN PENELITIAN}

Tujuan penelitian ini adalah:

1. Mengetahui hasil pelaksanaan program rintisan pengembangan pendidikan jarak jauh (PPJJ) dalam hal kesiapan pimpinan dalam pengimplementasian program.

2. Mengetahui hasil pelaksanaan program rintisan pengembangan pendidikan jarak jauh (PPJJ) dalam hal kesiapan sumber daya manusia.

3. Mengetahui hasil pelaksanaan program rintisan pengembangan pendidikan jarak jauh (PPJJ) dalam hal kesiapan sa- 
rana prasarana.

4. Memberikan masukan bagi tindak lanjut pelaksanaan program rintisan pengembangan pendidikan jarak jauh (PPJJ) di lingkup IAIN Walisongo Semarang.

\section{METODE DAN PROSEDUR PENELITIAN}

\section{Pendekatan Penelitian}

Penelitian ini menggunakan pendekatan kualitatif. Menurut Poerwandari (1998) penelitian kualitatif adalah penelitian yang menghasilkan dan mengolah data yang sifatnya deskriptif, seperti transkripsi wawancara, catatan lapangan, gambar, foto rekaman video dan lain-lain.

Dalam penelitan kualitatif perlu menekankan pada pentingnya kedekatan dengan orang-orang dan situasi penelitian, agar peneliti memperoleh pemahaman jelas tentang realitas dan kondisi yang terjadi (Patton dalam Poerwandari, 1998).

\section{Subyek Penelitian}

Subyek yang akan diteliti ialah pimpinan fakultas, dosen kelas online pada program rintisan PJJ sejumlah 10 orang, mahasiswa peserta kuliah online pada program rintisan PJJ serta PUSKOM selaku tim teknis pengelola sarana prasarana kelas online.

3. Metode Pengumpulan Data dan Pengolahan Data

a. Metode Pengumpulan Data

1) Wawancara

Wawancara dilakukan dengan menggunakan pedoman wawancara yang telah memuat topik atau isu yang terkait dengan pelaksanaan program rintisan PPJJ baik partisipasi, konteks sosial maupun organisasional.

2) Observasi

Observasi dilakukan dengan pedoman observasi. 
Menurut Patton (dalam Poerwandari 1998) tujuan observasi adalah mendeskripsikan setting yang dipelajari, aktivitas-aktivitas yang berlangsung, orang-orang yang terlibat dalam aktivitas, dan makna kejadian di lihat dari perpektif mereka yang terlihat dalam kejadian yang diamati tersebut. Pedoman observasi lebih dikhususkan untuk mengamati pelaksanaan pembelajaran dalam lingkup kelas online.

3) Dokumentasi

Dokumentasi digunakan untuk menginventarisasi subyek fisik yang berupa sarana prasarana yang menunjang pelaksanaan pembelajaran online dalam program rintisan PPJJ.

b. Metode pengolahan Data

Data yang terkumpul dianalisis dengan model evaluasi CIPP (Context, Input, Process, Product) yang dikembangkan oleh Stufflebeam (1971) (Worthen dan Sanders 1973). Menurut model ini ada empat aspek penyelenggaraan rintisan PJJ yang dapat dievaluasi: context, input, process, dan product.

\section{Metode Penyusunan Instrumen}

a. Instrumen wawancara

Instrumen wawancara digunakan sebagai pedoman untuk melakukan wawancara dengan jajaran pimpinan, ketua PUSKOM, dosen perancang kelas online serta mahasiswa peserta kelas online. Wawancara mengacu pada topik atau isu yang mampu menggambarkan bagaimana pandangan dan perilaku para subyek saat terlibat dalam pelaksanaan program rintisan PPJJ. Pada setiap jenis subjek disediakan pedoman atau instumen wawancara yang berbeda disesuaikan pada isu dan ruang lingkup tugas yang dilakukan. 
b. Instrumen pengamatan

Instrumen pengamatan digunakan sebagai pedoman untuk melakukan pengamatan terhadap pelaksanaan pembelajaran dalam kelas online khususnya interaksi antar mahasiswa, antara mahasiswa dengan konten serta interaksi antara dosen dan mahasiswa.

Pengamatan meliputi ketersediaan dan kelengkapan komponen-komponen kelas online yang ideal; kemampuan dosen dalam menyediakan media komunikasi interaktif dalam kelas online; serta partisipasi mahasiswa dalam memenuhi tugas-tugas dalam pembelajaran kelas online.

Form dokumentasi digunakan untuk menginventarisasi ketersediaan sarana prasarana baik secara kualitas maupun kuantitas. Macam sarana prasarana tersebut meliputi perangkat keras: komputer, infrastuktur jaringan beserta kondisi dan model pengaksesannya, ketersediaan smart class dsb. Sedangkan perangkat lunak meliputi ketersediaan sistem informasi terpadu di institusi beserta Learning Management System-nya.

\section{HASIL PENELITIAN}

\section{Pembelajaran Online Sebagai bagian dari Pengembangan Pembelajaran Jarak Jauh (PPJJ) di IAIN Walisongo}

Dalam Wikipedia, pembelajaran jarak jauh atau PJJ dirumuskan sebagai pembelajaran dengan menggunakan suatu media yang memungkinkan terjadi interaksi antara pengajar dan pembelajar. Dalam PJJ antara pengajar dan pembelajar tidak bertatap muka secara langsung, dengan kata lain melalui PJJ dimungkinkan antara pengajar dan pembelajar berbeda tempat bahkan bisa dipisahkan oleh jarak yang sangat jauh sehingga sangat memudahkan proses pembelajaran. Bentuk pembelajaran jarak jauh yang populer adalah e-learning atau elektronics learning atau pembelajaran berbasis elektronik dimana termasuk di 
dalamnya pembelajaran online.

Pembelajaran online di IAIN Walisongo memiliki aspekaspek keutamaan sebagai berikut:

\section{Fleksibilitas}

Berbeda dengan pembelajaran konvensional, pembelajaran online memberikan fleksibilitas dalam memilih waktu dan tempat untuk mengakses pelajaran. Peserta didik tidak perlu mengadakan perjalanan menuju tempat pelajaran disampaikan, e-learning bisa diakses dari mana saja yang memiliki akses ke internet. Bahkan, dengan berkembangnya mobile technology (dengan laptop, bahkan telepon selular jenis tertentu), semakin mudah mengakses e-learning. Dari respon dosen yang mengikuti PPJJ fleksibilitas pembelajaran online yang berlangsung membantu dalam menjembatani perkuliahan di kelas yang tidak dapat berlangsung. Mahasiswa juga lebih leluasa dalam mengikuti diskusi dan mengerjakan tugas mandiri.

Menjangkau mahasiswa dalam cakupan yang luas (potential to reach a global audience). Dengan fleksibilitas waktu dan tempat, maka jumlah peserta didik yang dapat dijangkau melalui kegiatan pembelajaran elektronik semakin lebih banyak atau meluas. Ruang dan tempat serta waktu tidak lagi menjadi hambatan. Siapa saja, di mana saja, dan kapan saja, seseorang dapat belajar. Interaksi dengan sumber belajar dilakukan melalui internet. Kesempatan belajar benar-benar terbuka lebar bagi siapa saja yang membutuhkan.

\section{Pembelajaran Mandiri (Independent Learning)}

E-learning memberikan kesempatan bagi dosen untuk memegang kendali atas kesuksesan mahasiswa masing-masing, artinya dosen diberi kebebasan untuk menentukan kapan akan mulai, kapan akan menyelesaikan, dan bagian mana dalam satu modul yang ingin dipelajarinya terlebih dulu. Perkuliahan bisa dimulai dari topik-topik ataupun halaman yang menarik minatnya terlebih dulu, ataupun bisa melewati saja bagian yang dianggap sudah mahasiswa kuasai. Jika mahasiswa mengalami 
kesulitan untuk memahami suatu bagian, mahasiswa bisa mengulang-ulang lagi sampai ia merasa mampu memahami. Seandainya, setelah diulang masih ada hal yang belum mahasiswa pahami, pembelajar bisa menghubungi instruktur, atau dosen melalui email atau ikut dialog interaktif pada waktu-waktu tertentu. Jika mahasiswa tidak sempat mengikuti dialog interaktif, mahasiswa bisa membaca hasil diskusi di message board yang tersedia di LMS (di Website Dosen). Banyak mahasiswa yang merasa cara belajar independen seperti ini lebih efektif daripada cara belajar lainnya yang memaksakannya untuk belajar dengan urutan yang telah ditetapkan.

Di Kelas kadar interaksi pembelajaran antara mahasiswa dengan dosen atau pada pembelajaran yang bersifat konvensional, kesempatan yang ada atau yang disediakan dosen untuk berdiskusi atau bertanya jawab sangat terbatas. Kesempatan yang terbatas ini juga cenderung didominasi oleh beberapa peserta didik yang cepat tanggap dan berani. Dengan PTK-online dapat menjembatani mahasiswa yang kurang berani untuk menyampaikan pendapat dalam diskusi di kelas.

\section{Biaya}

Biaya yang bisa dihemat dari cara pembelajaran dengan e-learning tidak hanya dari segi finansial tetapi juga dari segi non-finansial. Secara finansial, biaya yang bisa dihemat, antara lain biaya transportasi ke tempat kuliah dan akomodasi selama biaya administrasi pengelolaan, penyediaan sarana dan fasilitas fisik untuk belajar (misalnya: penyewaan ataupun penyediaan kelas, kursi, papan tulis, LCD player, OHP). Mahasiswa mendapat fasilitas hostpot dan enternet gratis dalam jangka waktu tertentu dalam satu semester. Hal ini akan semakin menghemat biaya yang dikeluarkan. Namun ada juga mahasiswa dan Dosen yang harus mengeluarkan biaya tambahan untuk mensukseskan kelas on line yang berlangsung.

Namun demikian, pembelajaran online membutuhkan sarana prasarana tertentu. Selain harus tersedia, sarana prasarana ini juga harus dipelihara atau dikelola. Sarana tersebut dapat be- 
rupa sarana perangkat keras dan sarana perangkat lunak.

Infrastruktur perangkat keras yang tersedia meliputi :

1) Komputer yang terhubung ke jaringan LAN dan WAN

2) Ketersediaan infrastruktur jaringan baik kabel mapun wireless.

Ketersediaan perangkat lunak meliputi:

1). Ketersediaan sistem Learning Management System dalam manajemen sistem informasi institut yang belum maksimal dalam member dukungan untuk pembelajaran online

2). Sebagai pendukung, LMS disupport dengan perangkat-perangkat lunak yang mendukung pengadaan media berbasis komputer (audiovisual aid).

Pembelajaran online tidak saja membutuhkan sarana berbeda, namun dalam sisi pendekatan juga diatur sedemikian rupa agar penggunaan teknologi dalam pembelajaran online tidak lebih mempersulit bentuk pembelajaran konvensiaonal.

Tabel 3. Ketersediaan Komponen Kelas Online

\begin{tabular}{|c|l|l|}
\hline No & Topik & $\begin{array}{l}\text { Indikator Komponen Kelas } \\
\text { Ideal }\end{array}$ \\
\hline 1 & $\begin{array}{l}\text { Pengorganisasian } \\
\text { konten }\end{array}$ & Urutan sesi logis \\
\hline 2 & Pengorganisasian sesi & Organisasi sesi konsisten \\
\hline 3 & Laman utama & Informasi ada dan relevan \\
\hline 4 & Navigasi & $\begin{array}{l}\bullet \text { Bersyarat } \\
\bullet \text { Navigasi user friendly }\end{array}$ \\
\hline 5 & Elemen rancangan & $\begin{array}{l}\bullet \text { Konsisten dalam warna } \\
\text { Konsisten dalam } \\
\text { ketersediaan objek }\end{array}$ \\
\hline
\end{tabular}

40 Jurnal PHENOMENON, Volume 2 Nomor 1, Juli 2012 


\begin{tabular}{|c|l|l|}
\hline 6 & Interaktifitas & $\begin{array}{l}\text { Tersedia } \\
\text { Interaksi antar mahasiswa } \\
\text { Interaksi antar mahasiswa } \\
\text { dengan konten } \\
\bullet\end{array}$ \\
$\begin{array}{c}\text { Interaksi pembelajar dengan } \\
\text { pengajar }\end{array}$ \\
\hline 7 & Gambaran umum & $\begin{array}{l}\text { Ketersediaan gambaran } \\
\text { umum }\end{array}$ \\
\hline 8 & Tujuan & Ketersediaan Tujuan \\
\hline 9 & Persyaratan kelas & $\begin{array}{l}\text { Ketersediaan Persyaratan } \\
\bullet \text { Waktu } \\
\bullet \text { Ekspektasi }\end{array}$ \\
\hline 10 & Sesi Pengantar & Ketersediaan Sesi Pengantar \\
\hline 12 & Bacaan & Ketersediaan Bacaan \\
\hline 13 & Kegiatan & Ketersediaan Kegiatan \\
\hline 14 & Diskusi & Ketersediaan Diskusi \\
\hline 15 & Assesment & Ketersediaan Assesment \\
\hline
\end{tabular}

\section{Program Rintisan Pengembangan Pendidikan Jarak Jauh DBE2-IAIN Walisongo Semarang}

Program rintisan oleh DBE2 dikelola secara terpadu melalui portal http://ptk-online.org. DBE2 menyediakan portal tersebut sebagai media berkomunikasi, media pelatihan dan media pendampingan antar seluruh peserata program rintisan PPJJ ini. 


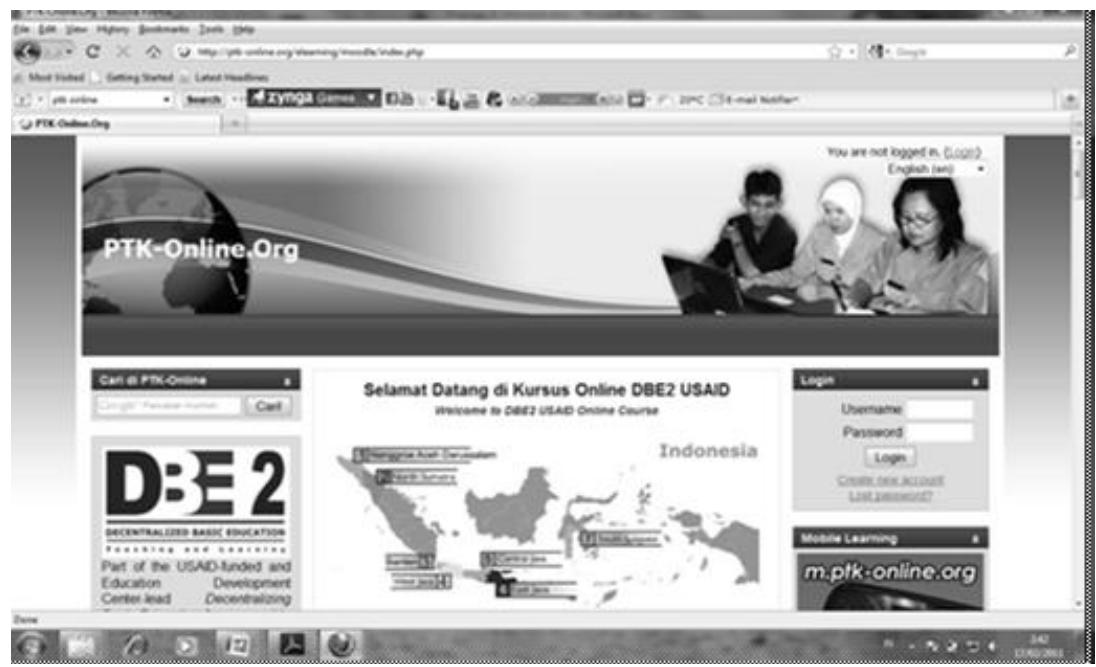

Gambar 2. Halaman Utama Website ptk-online.org

Setiap stakeholders (11 perguruan tinggi) diberi akses untuk masuk ke dalam portal. Setiap peserta dari setiap stakeholders memiliki hak akses tertentu dengan dilengkapi username dan password dalam mengakses portal. Portal memuat informasi apa saja terkait perkembangan program juga konten pelatihan dan pendampingan yang sedang diselenggarakan.

Secara umum, struktur portal ptk-online.org dirancang untuk dapat diakses dengan tahapan dan fungsionalitas umum adalah sebagai berikut:

1. Halaman Utama, dengan sejumlah informasi ter-update

2. Sistem akses dengan login (username dan password) menggunakan nama dan NIM mahasiswa

3. Kelas online bagi setiap mahasiswa

4. Ruang interaksi antar mahasiswa 


\section{Pelaksanaan Program Rintisan PPJJ di IAIN Walisongo Semarang}

IAIN Walisongo melalui Fakultas Tarbiyah memulai kerjasama rintisan ini. Berkaitan dengan pelaksanaan program, komponen yang disediakan oleh Fakultas adalah sebagai berikut:

\section{Tahap Rintisa}

1. Penyediaan sumber daya dosen sejumlah 10 orang. Lima dosen mengikuti pelatihan sebagai OCD dan lima dosen lainnya mengikuti pelatihan sebagai OPDD.

2. Jaringan internet di IAIN Walisongo

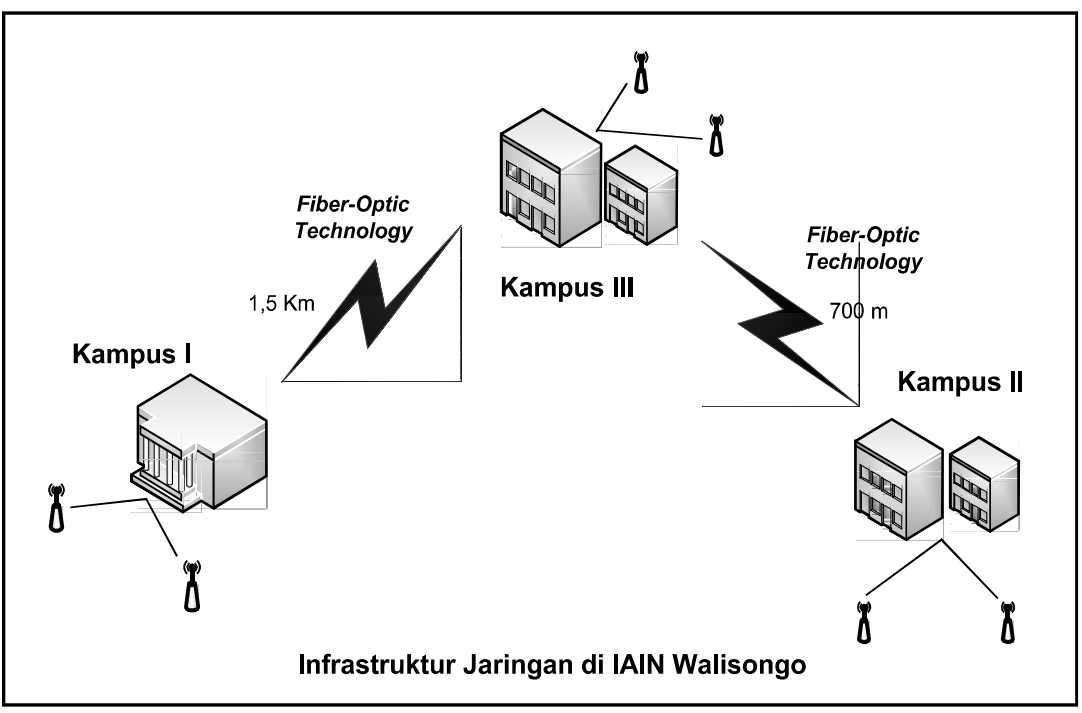

\section{Gambar 4. Infrastruktur Jaringan di IAIN Walisongo}

3. Kebutuhan kesiapan pengguna dalam hal ini keahlian berinteraksi dengan pembelajaran online (variasi bentuk media interaksi dalam pembelajaran yang berbasis elektronik).

Selain itu, tersedia pula fasilitas lain misal ketersediaan Smart Class. Smart Class adalah ruang kelas yang dilengkapi dengan piranti teknologi seperti komputer dengan koneksi online 
serta LCD proyektor. Adapun data ketersediaan Smart Class di setiap Fakultas adalah sebagai berikut:

Tabel 2. Ketersediaan Smart Class*

\begin{tabular}{|l|c|c|}
\hline Jumlah Ruang & $\begin{array}{c}\text { LCD atau LCD+Komputer } \\
\text { (dengan koneksi Online) }\end{array}$ & Hot Spot \\
\hline Fak. Tarbiyah \\
\hline 25 & 25 & 3 \\
\hline Fak. Syariah & 2 \\
\hline 24 & 12 & 2 \\
\hline Fak. Ushuludin & 8 \\
\hline \multicolumn{2}{|c|}{10} & 11 \\
\hline Fak. Dakwah & \\
\hline 12 &
\end{tabular}

Catatan:

* KaSubag Perlengkapan di 4 Fakultas (Desember 2010)

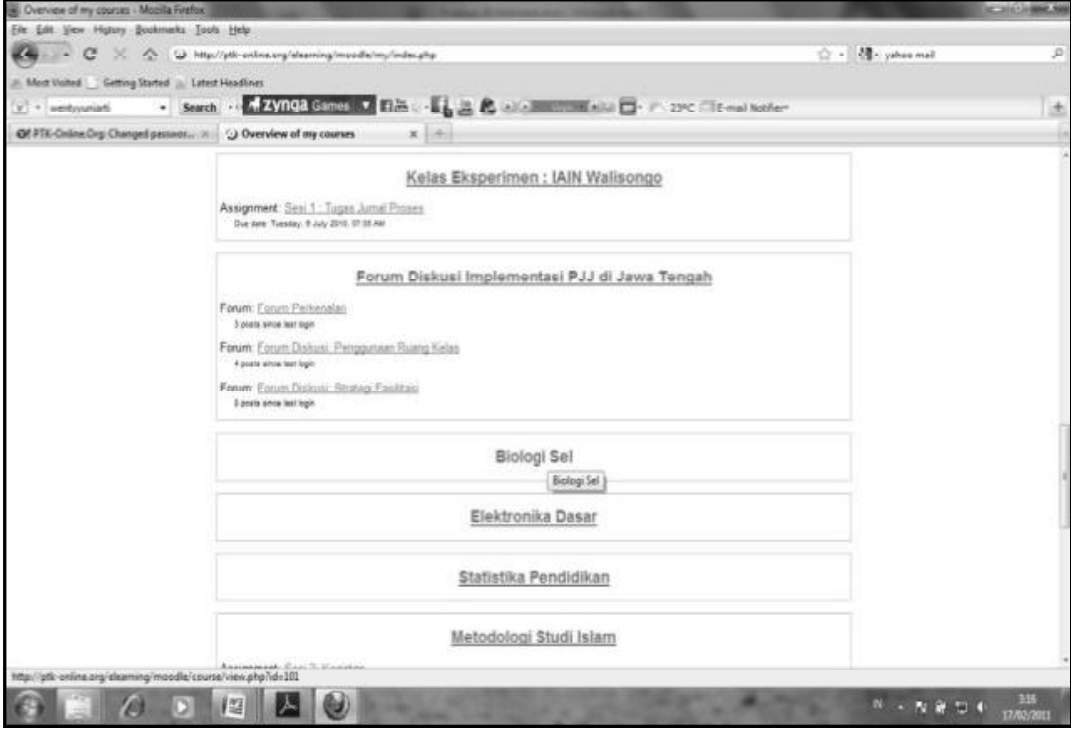

Gambar 5. Overview Kelas Online di ptk-online.org 
Gambar 5 menunjukkan kelas online yang dirancang oleh dosen peserta program rintisan yang terintegrasi dalam ptk-online.org. Kelas online ini hanya dapat terakses jika peserta memasukkan username dan password yang direkomendasikan.

\section{KESIMPULAN}

Dari pembahasan di atas dapat disimpulkan bahwa:

1. Pimpinan memberikan dukungan pada implementasi PPJJ namun belum maksimal dalam memberikan dukungan infrastruktur.

2. Kesiapan sumber daya manusia baik dosen dan mahasiswa sudah cukup memenuhi untuk implemnetasi PPJJ.

3. Ketersediaan sarana dan prasanana yang menjadi fasilitas dan daya dukung untuk PPJJ kurang terpenuhi karena LMS yang belum berfungsi secara maksimal

4. PPJJ mendapat tanggapan dan dukungan dari berbagai pihak terutama dosen dan mahasiswa, sehingga perlu untuk ditindaklanjuti.

\section{REKOMENDASI}

Hasil penelitian ini dapat sebagai rekomendasi dalam:

1. Mendukung internalisasi teknologi dalam pelaksanaan pembelajaran di IAIN Walisongo Semarang dalam rangka inovasi serta peningkatan mutu kualitas akademik.

2. Secara khusus, mendukung pengembangan Learning Management System (LMS) di IAIN Walisongo Semarang, dan secara umum mengoptimalisasi ketersediaan sarana prasarana teknologi di IAIN Walisongo Semarang.

3. Bagi pimpinan, diperolehnya suatu bentuk pelaksanaan pembelajaran yang bertujuan meningkatkan kualitas mutu akademik.

4. Bagi para dosen, diperolehnya suatu bentuk pembelajaran yang mendukung dosen untuk tidak gagap teknologi dan terbiasa berinteraksi dengan kemajuan teknologi pendidikan.

5. Bagi mahasiswa, diperolehnya bentuk pembelajaran yang 
Nur Khasanah

lebih variatif dan inovatif sehingga semakin mendukung keberhasilan pelaksanaan belajar mengajar.

6. Lembaga, khususnya Fakultas Tarbiyah dan IAIN Walisongo pada umumnya, memiliki prototype pembelajaran online yang perlu ditindaklanjuti lebih serius sebagai daya saing institusi. 


\section{DAFTAR PUSTAKA}

Burns, M. \& Dimock, K.V. (2007). Technology as a catalyst for school communities: Beyond boxes and bandwidth. Lanham, MD: Rowman \& Littlefield.

Data Pengguna Internet di Indonesia, Rakernas APJII 2010.

Elemen dalam Sebuah Kelas Online, EdTech Leader Online.

Fadllan, Andi, “Evaluasi Pembelajaran Mata Kuliah Keterpaduan Iptek Islam Sebagai Upaya Menyusun dan Merumuskan Konsep Integrasi Sains dan Agama di IAIN Walisongo", (Penelitian Individual Puslit IAIN Walisongo, 2008)

Ismail SM, "Studi tentang Peningkatan Mutu Akademik melalui Implementasi Strategi Pembelajaran Aktif (Active Learning) di IAIN Walisongo Semarang", (Penelitian Individual Puslit IAIN Walisongo, 2007).

Kamus Besar Bahasa Indonesia, Departemen Pendidikan dan Kebudayaan: Balai Pustaka, 1990.

Kerangka Acuan Kerjasama Antara Decentralized Basic Education 2 (DBE2) dengan IAIN Walisongo Semarang, 2 Desember 2010.

Muntholi'ah, M.Pd. dkk., "Kompetensi Guru Pendidikan Agama 
Islam Pasca Lulus Sertifikasi Guru (Studi Kasus Guru PAI Bersertifikat Pendidik di Provinsi Jawa Tengah)“, (Penelitian Kelompok Kompetitif, Dit Diktis Ditjen Pendis Kemenag RI, 2010).

Oetomo, B.S.D dan Priyogutomo, Jarot. 2004. Kajian Terhadap Model e-Media dalam Pembangunan Sistem e-Education, Makalah Seminar Nasional Informatika 2004.

Onno W. Purbo (1998), Alternatif Teknologi untuk Pendidikan Jarak Jauh, Computer Network Research Group, Bandung: Institut Teknologi Bandung.

Peraturan Pemerintah RI Nomor 17 Tahun 2010 Tentang Penyelanggaraan Pendidikan Jarak Jauh (PJJ).

Poerwandari, E. Kristi (1998 ), Pendekatan kualitatif dalam Penelitian Psikologi, Penerbit: Jakarta: LPSP3 FP-UI.

Rodriguez, J.I., Plax, T.G., \& Kearney, P. (1996, Oktober). Clarifying the relationship between teacher nonverbal immediacy and student cognitive learning. Dalam Communication Education, 45(4), 293-305.

Suara Merdeka, Penguatan Edukasi Berbasis Elektronik, Semarang: Suara Merdeka, 5 Februari 2011.

Sumanto,.Metode Penelitian Sosisl dan Pendidikan, Yogyakarta: Andi Offset, 1995.

Undang-undang RI Nomor 20 Tahun 2003 Tentang Sistem Pendidikan Nasional. 